\title{
Impact of Fusarium verticillioides on chlorophyll fluorescence parameters of two maize lines
}

\author{
Farhad Baghbani • Ramin Lotfi • \\ Sajjad Moharramnejad • Ali Bandehagh • \\ Mozaffar Roostaei • Anshu Rastogi • Hazem M. Kalaji
}

Accepted: 5 December 2018 / Published online: 19 January 2019

(C) The Author(s) 2018

\begin{abstract}
Fusarium verticillioides is one of the most common phytopathogenic fungi affecting maize production, worldwide. The early identification of $F$. verticillioides infection in maize could be helpful to prevent the spreading of the fungus. Therefore, this study represents the use of chlorophyll fluorescence parameters to identify $F$. verticillioides infection in
\end{abstract}

F. Baghbani

Department of Agriculture, Payame Noor University, Tehran, Iran

R. Lotfi • M. Roostaei

Dryland Agricultural Research Institute, Agricultural Research

Education \& Extension Organization, Maragheh, Iran

S. Moharramnejad

Seed and plant Improvement Institute, Ardabil Agricultural and

Natural Resources Research Center, AREEO, Moghan, Iran

A. Bandehagh

Department of Plant Breeding and Biotechnology, Faculty of

Agriculture, University of Tabriz, Tabriz, Iran

A. Rastogi $(\bowtie)$

Department of Meteorology, Poznan University of Life Sciences, Piatkowska 94, 60-649 Poznan, Poland

e-mail: anshu.rastogi@up.poznan.pl

H. M. Kalaji

White Hill Company, Żurawia 71/3, 15-540 Białystok, Poland

H. M. Kalaji $(\bowtie)$

Institute of Technology and Life Sciences (ITP), Falenty, $3 \mathrm{Al}$.

Hrabska, 05-090 Raszyn, Poland

e-mail: hazem@kalaji.pl maize. Chlorophyll a fluorescence of control and F. verticillioides infected plants showed a typical polyphasic OJIP transient curve in both MO17 and B73 lines. Infected plants from both maize lines showed a different pattern of OJIP transient curve when compared to the control plants, respectively. This indicated that $F$. verticillioides had an effect on the photosynthesis of infected maize plants. This study demonstrated the importance of parameters such as: the activity of the watersplitting complex on the donor side of PSII $\left(\mathrm{F}_{\mathrm{v}} / \mathrm{F}_{0}\right)$, minimum fluorescence $\left(\mathrm{F}_{0}\right)$, maximum fluorescence $\left(\mathrm{F}_{\mathrm{m}}\right)$, and absorption flux per one active reaction center $(\mathrm{ABS} / \mathrm{RC})$ to identify $F$. verticillioides infection in maize.

Keywords Chlorophyll a fluorescence $\cdot$ Fusarium verticillioides $\cdot$ Maize $\cdot$ Photosynthesis

\section{Introduction}

Maize (Zea mays L.) plays a key role in the diet of millions of people throughout the world. Many pests and parasites frequently attack maize plants. Several phytopathogenic species of the Fusarium genus have been observed to be associated with maize, including Fusarium verticillioides (Saccardo) Nirenberg (teleomorph Gibberella moniliformis Wineland). Fusarium verticillioides is a fungal pathogen with a wide range of plant hosts such as maize, sorghum, rice (Blacutt et al. 2018). Fusarium verticillioides has been associated with severe diseases on the roots, stems, 
leaves, ears and tassels of maize plants (Kommedahl and Windels 1981). The disease symptoms vary widely from asymptomatic to severe rotting of maize plants (Oren et al. 2003). Maize rot disease caused by F. verticillioides may severely affect maize production and grain quality. Due to global warming the disease has been reported to spread around the world (Duan et al. 2016). In addition to causing disease to maize, $F$. verticillioides infection may also result in food safety problems for humans and animals as the fungus produces highly toxic mycotoxins in infected cereals, which is not easily removable or detoxified from the grains (Gelderblom et al. 1988). The mycotoxins from Fusarium species were considered among the research priorities of the World Health Organization and the Food and Health Organization (Duan et al. 2016), and even after several years of research, it still remains a serious problem for the world. Fumonisins are a common mycotoxins produced by Fusarium species and are currently considered to be the most agriculturally significant environmental toxins produced in the field or during storage (Desai et al. 2002). Fumonisins have been detected from both asymptomatic and symptomatic maize kernels and thus the control of fumonisins in maize has become a research priority (Oren et al. 2003). Fusarium verticillioides affects plant growth and development by interfering with plant physiological processes. Pshibytko et al. (2006) have previously reported that Fusarium wilt inhibits photosynthetic activity in tomato plants. The authors have concluded that the impact was due to the damage to Photosystem II (PSII). Several other reports have also shown a clear reduction in photosynthetic activity of plants as a result of fungal infection (Bassanezi et al. 2002; Zhori et al. 2015)

High time-resolution measurements of the chlorophyll a fluorescence $(\mathrm{ChlF})$ transient represents a particularly quick method for gaining detailed information about PSII photochemical activity, electron transport events and the different regulatory processes (Schansker et al. 2006). In recent times, ChlF measurements are gaining popularity as a technique to identify plant stress (Baker and Rosenqvist 2004; Baker 2008; Borawska-Jarmułowicz et al. 2014; Bouthour et al. 2015; Kalaji et al. 2018). The time dependent increase in ChlF intensity with application of continuous bright light to a previously dark-adapted sample is used to calculate fast ChlF kinetics data. The curve drawn from the fast ChlF kinetics data is defined as Kautsky curve or the ChlF transient curve (Schansker et al. 2005; Cepl et al. 2016). With the analysis of the ChlF transition curve, it is possible to evaluate the plant vitality under stress conditions. The fluorescence parameters measured through the ChlF transition curve, defined as JIP test (Force et al. 2003) depicts the functionality of PSII (Schansker et al. 2006). Therefore, it is possible to quantify the stepwise flow of energy through PSII using JIP-test. Schansker et al. (2005) has shown a simplified model of the energy fluxes using the input data from the fluorescence transient, which incorporated different parameters defining types of fluxes, such as absorption flux (ABS), electron transport flux (ET), trapping flux (TR), and the flux defining the dissipation of non-trapped energy as heat (DI). Stirbet and Govindjee (2011), later extended the flux list by adding a flux to quantify the reduction of photosystem I (PSI) end acceptor (RE).

Chlorophyll a fluorescence kinetics studies using portable devices known as fluorometers or Plant Stress Meters (PSM) is one of the finest methods to investigate the function of PSII and its reactions to changes in the environment and plant growth conditions (Kalaji et al. 2011). In recent years, changes in $\mathrm{ChlF}$ patterns in response to several stress factors has been reported, such as, drought (Berger et al. 2010; Živčák et al. 2014; de Sousa et al. 2017), low or high light (Bartak et al. 2004; Kalaji et al. 2012; Hazrati et al. 2016), salinity (Zhang et al. 2010; Kalaji et al. 2011), temperature (Kalaji et al. 2011; Brestič et al. 2012; Botta 2013; Huang et al. 2017) and herbicides (Balabanova et al. 2016). Nevertheless, photosynthetic performances of different maize lines by exploiting multi-parametric fluorescence devices under inoculation with $F$. verticillioides have not yet been explored at all. Thus, the main aim of this research was to evaluate the effects of $F$. verticillioides on the light dependent phase of photosynthesis in two maize lines (MO17 and B73). The study also demonstrates that fast chlorophyll fluorescence kinetics can be useful for rapid and noninvasive detection of the infected maize plants in the field.

\section{Materials and methods}

Plant materials and growth conditions

The maize lines MO17 and B73 were selected for this study as they represent important inbred lines, and are the most common maize lines used in hybridization. A pot experiment in a randomized complete block (RCB) design with three replicates was conducted in 2016 (University of Tabriz, Tabriz, Iran). For the purpose of the investigation, 
five maize seeds were sown at a depth of $5 \mathrm{~cm}$ in each pot $(25 \times 25 \mathrm{~cm})$ containing soil (soil mixture contained $30 \%$ sand, $39 \%$ silt, $41 \%$ clay, and soil $\mathrm{pH}$ was 7.8 ). All pots were kept inside a greenhouse under natural light with the minimum and maximum temperature ranging between 25 to $30{ }^{\circ} \mathrm{C}$, respectively. After seedling establishment, the plants were thinned to three plants per pot.

Fusarium verticillioides preparation

Fusarium verticillioides isolates were collected from Seed and Plant Improvement Institute, Karaj, Iran. The isolated fungi were cultured on potato dextrose agar (PDA) and grown under $12 \mathrm{~h}$ light and $12 \mathrm{~h}$ dark condition at 20 to $25^{\circ} \mathrm{C}$, respectively.

A Fusarium verticillioides spore suspension for plant inoculation was prepared in distilled water containing $0.1 \%$ Tween 20 , and adjusted to $\sim 2 \times 10^{5}$ spores per $\mathrm{ml}$ by using a hemocytometer. At the 4-6 leaf stage, the spore suspension was sprayed on the leaves of maize plants. All control plants were sprayed with distilled water containing $0.1 \%$ Tween 20 only. All the physiological responses of maize plants were measured five days after inoculation.

Pigments content and stomatal conductance measurement

Chlorophyll content was determined using the methods proposed by Harborne (1984). The upper fully expanded leaves of maize plants were detached five days after inoculation. Prior to extraction, fresh leaf samples were washed with deionized water to remove any surface contamination, thereafter the pigments were extracted from $1 \mathrm{~g}$ of the leaf tissues by using $80 \%$ acetone. The extracted pigments were measured by an UV-visible spectroscopic method as described in the protocol by Lichtenthaler and Buschmann (2001). At the same stage, the stomatal conductance was monitored with an AP4 leaf porometer (Delta-T Devices Ltd., UK).

\section{Chlorophyll a fluorescence measurement}

Five days after the inoculation of plants with F. verticillioides, the induction of ChlF (OJIP transient) was monitored with a portable fluorometer (Handy Plant Efficiency Analyzer, Hansatech Instruments Ltd., UK). Prior to fluorescence signal measurement the plants were allowed to adapt to dark conditions for at least $30 \mathrm{~min}$. Measurements were carried out in the middle area of the

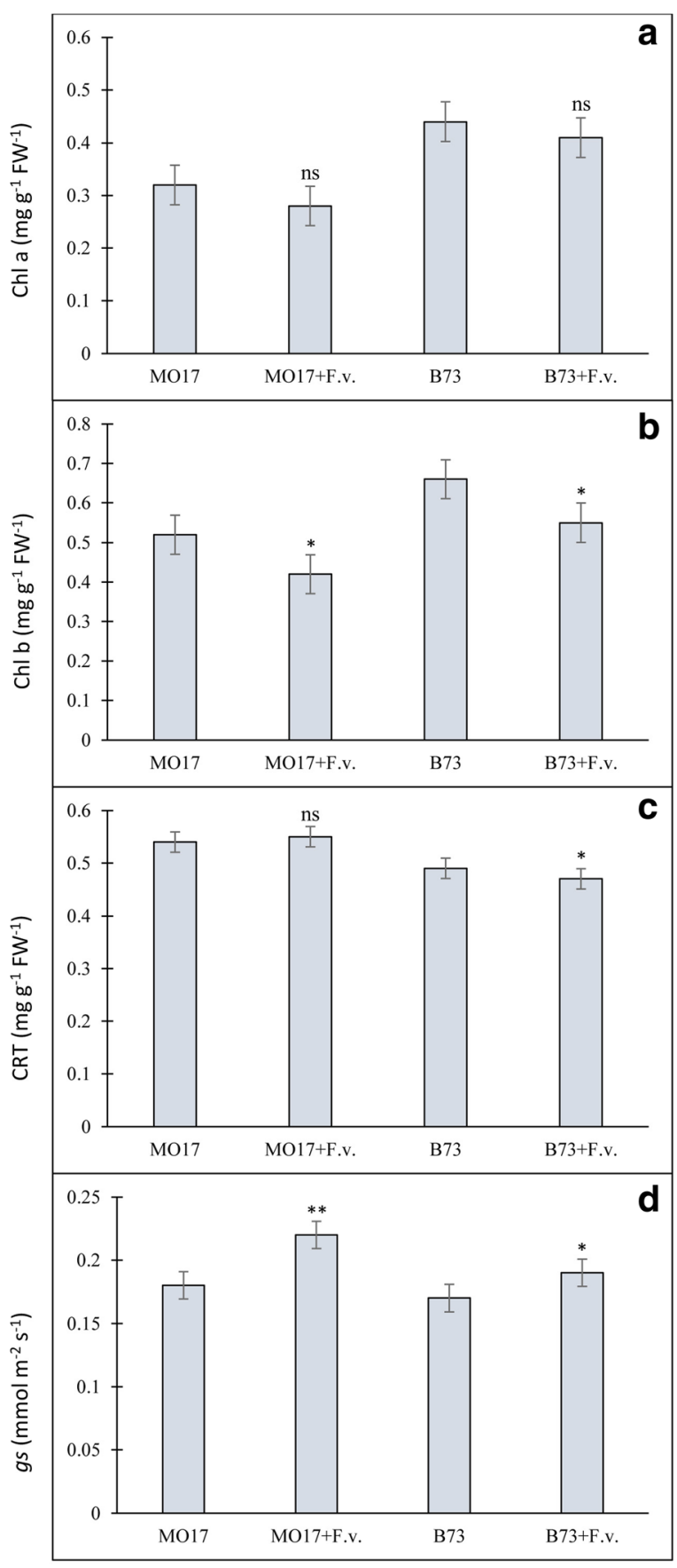

Maize lines

Fig. 1 Effect of $F$. verticillioides on pigments content $(\mathbf{a}, \mathbf{b}, \mathbf{c})$ and stomatal conductance (d) of two maize lines

upper surface of the fully developed leaves of the control and $F$. verticillioides infected plants. For each condition, three measurements were recorded from three different plants. The OJIP curve was drawn from the mean values 
Fig. 2 Effect of $F$. verticillioides on ChlF transition curve: Effects of Fusarium verticillioides on OJIP curve of two maize lines are shown as fluorescence intensity (a) and as a relative variable fluorescence (b)

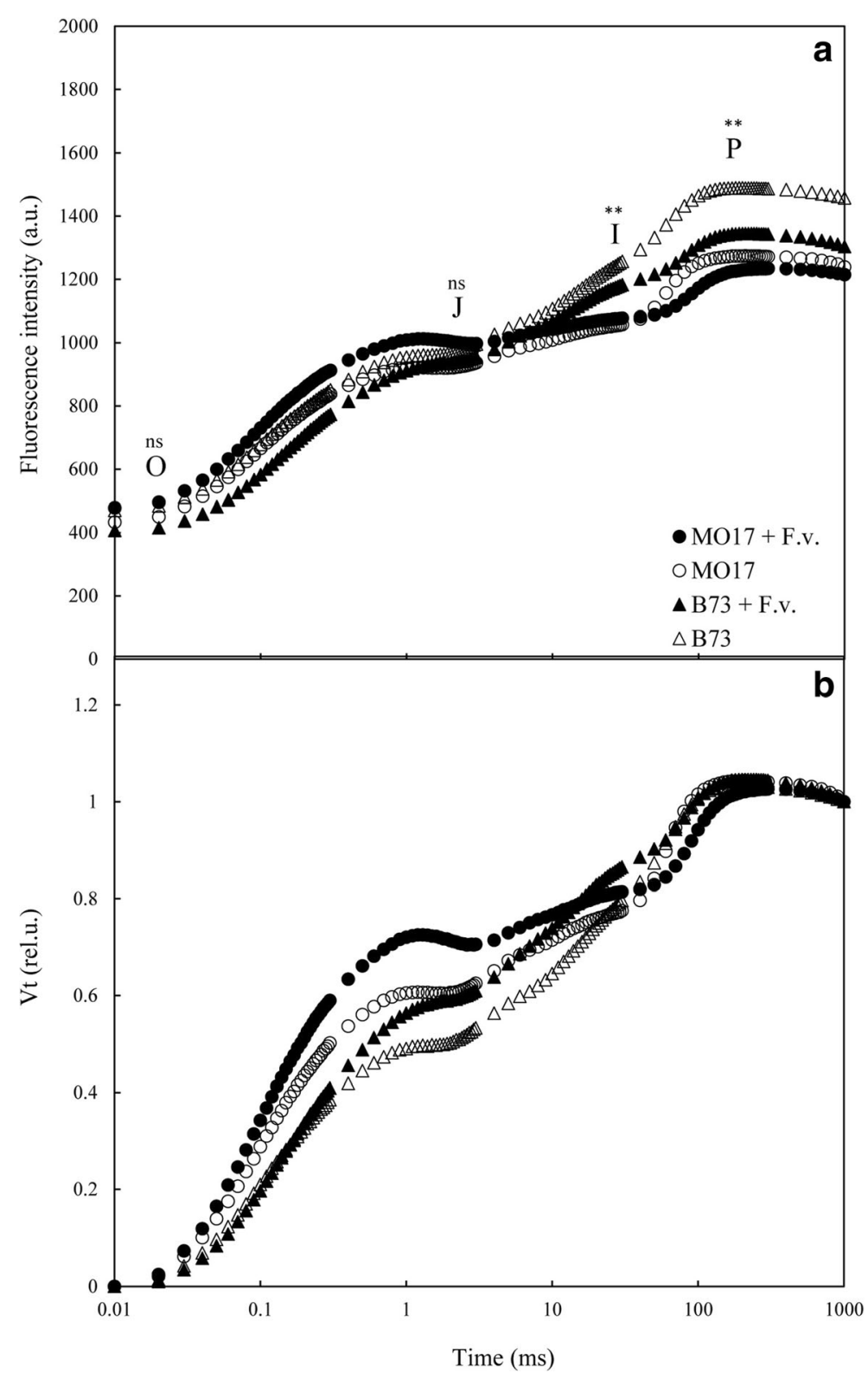

of three different data points obtained. Several expressions and fluorescence parameters were calculated from the OJIP transient recorded during the first seconds of measurement.

\section{Statistical analysis}

All the data were analyzed based on the experimental design, using SAS 9.1 software (SAS Institute, USA). The means of each trait were compared to control according to the Duncan multiple range test at $p \leq 0.05$.

\section{Results}

Pigment content and stomatal conductance

The concentration of chl a and chl b were observed to be lowered in both maize lines as the result of $F$. verticillioides infection. However, only a decrease in chl $\mathrm{b}$ content was observed to be significant for both maize lines. No significant decrease in plant carotenoids content was observed for infected or non-infected maize lines (Fig. 1). 


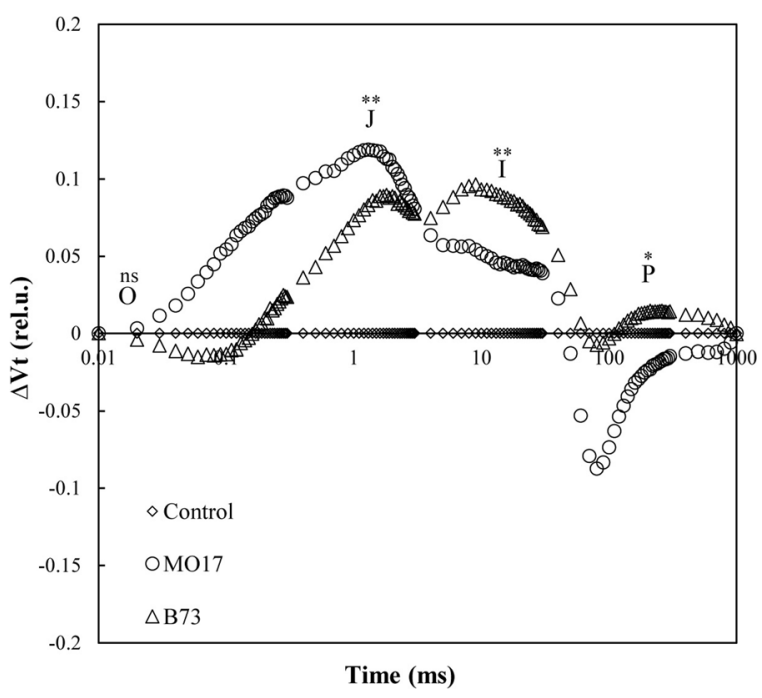

Fig. 3 Effect of $F$. verticillioides on OJIP fluorescence kineticsEffects of $F$. verticillioides on OJIP fluorescence kinetics analyzed by calculating the difference in the variable fluorescence curves $(\Delta \mathrm{Vt})$ at different time intervals

Stomatal conductance $\left(\mathrm{g}_{\mathrm{s}}\right)$ in both the maize lines were observed to be slightly increased as a result to F. verticillioides infection (Fig. 1d).

\section{Chlorophyll a fluorescence OJIP transient}

The control and infected plants (with F. verticillioides) showed a typical polyphasic rise in ChlF transient curve in both MO17 and B73 maize lines. The curve was plotted from the mean of three different data points (According to Duncan's multiple range test $p<0.05$ ). A significant decrease in the I$\mathrm{P}$ phase of the ChlF transient curve was observed in the $F$. verticillioides infected B73 line (Fig. 2a). To better visualize the effect of the $F$. verticillioides on the transient dynamics, the curves were plotted as relative variable fluorescence, $V_{t}=\left(F_{t}-F_{0}\right) /\left(F_{m}-\right.$ $\mathrm{F}_{0}$ ). Infection of plants with $F$. verticillioides significantly increased the ChlF levels at J-step $\left(\mathrm{V}_{\mathrm{J}}\right)$ in MO17 line, whereas the J-step $\left(\mathrm{V}_{\mathrm{J}}\right)$ in infected B73 line was slightly higher than non-infected B73 (Fig. 2b). A non-significant increase in $\mathrm{I}\left(\mathrm{V}_{\mathrm{I}}\right)$ and $\mathrm{P}\left(\mathrm{V}_{\mathrm{P}}\right)$ phases was observed in both the lines when infected with $F$. verticillioides (Fig. 2b).

Changes in OJIP fluorescence rise kinetics were obtained by calculating the differences in relative variable fluorescence curves, which were constructed by subtracting the normalized fluorescence values (between $\mathrm{O}$ and $\mathrm{P}$ ) recorded for the control plants from those recorded for plants infected with F. verticillioides $\left(\Delta \mathrm{V}=\mathrm{V}_{\mathrm{t}}(\mathrm{Xh})-\mathrm{V}_{\mathrm{t}}(\mathrm{oh})\right)$ (Fig. 3). The curves were calculated and plotted from the mean of three different data points. This analysis showed the appearance of $\Delta_{\mathrm{J}}$ (at $2 \mathrm{~ms}$ ) and $\Delta_{\mathrm{P}}$ (at $100 \mathrm{~ms})$ peaks in the MO17 and $\Delta_{\mathrm{K}}(0.3 \mathrm{~ms}), \Delta_{\mathrm{J}}$ (2 ms), $\Delta_{\mathrm{I}}(30 \mathrm{~ms})$ and $\Delta_{\mathrm{P}}(300 \mathrm{~ms})$ peaks in B73 line. The MO17 cultivar line was observed with a positive $\Delta \mathrm{Vt}$ values from $\mathrm{O}$ until the induction transient I-P, where the $\Delta \mathrm{Vt}$ values turned negative towards $\mathrm{P}$. In contrast, a negative induction at Lband was recorded in B73, then this curve turned positive towards $\mathrm{P}$. Positive $\Delta \mathrm{Vt}$ values indicated lower electron transportation rates, i.e., a decrease in the efficiency of electron transport with negative values.

For a detailed analysis of $F$. verticillioides induced changes in OJIP fluorescence rise kinetics, the differential curves during $\mathrm{O}$ to $\mathrm{P}$ transients was presented (L-, K-, J-, I- and G-bands). The curves for these bands were constructed by subtracting the normalized fluorescence values between $\mathrm{O}-\mathrm{K}, \mathrm{K}$ J, J - I, and I - P phases. The curves were calculated and plotted from the mean of three different data points. The ChlF transients of the two lines were double normalized between $F_{0}(0.05 \mathrm{~ms})$ and $F_{K}$ $(0.3 \mathrm{~ms})$, which can be expressed as $\mathrm{W}_{\mathrm{OK}}=\left(\mathrm{F}_{\mathrm{t}}-\right.$ $\left.\mathrm{F}_{\mathrm{o}}\right) /\left(\mathrm{F}_{\mathrm{K}}-\mathrm{F}_{\mathrm{o}}\right)$. Subsequently, the control transient was subtracted from the transients of the treated leaves $\left(\Delta \mathrm{W}_{\mathrm{OK}}\right)$. The difference in transients made a negative L-band $(0.15 \mathrm{~ms})$ visible in $\mathrm{B} 73$, but the value was observed to be positive in MO17. A negative deviation indicated the transformation of a sigmoidal fluorescence rise toward an exponential rise (Strasser and Stirbet 1998) with an increase in energetic connectivity (or grouping) between PSII units (Fig. 4a).

ChlF transients were also double normalized between $F \mathrm{k}$ and $F_{\mathrm{J}}(=0.3$ and $3 \mathrm{~ms})$, which was expressed as $\mathrm{W}_{\mathrm{KJ}}=\left(\mathrm{F}_{\mathrm{t}}-\mathrm{F}_{\mathrm{K}}\right) /\left(\mathrm{F}_{\mathrm{J}}-\mathrm{F}_{\mathrm{K}}\right)$, and again the difference between treated plants and control was determined $\left(\Delta \mathrm{W}_{\mathrm{OJ}}\right)$. Both of the maize lines showed positive values during the time range. $\mathrm{K}$ band was not observed during this time range (Fig. 4b). Double normalized ChlF data during $3 \mathrm{~ms}$ to $30 \mathrm{~ms}$ and from $30 \mathrm{~ms}$ to the time to reach $F_{m}$ was drawn to provide $\Delta \mathrm{W}_{\mathrm{JI}}$ and $\Delta \mathrm{W}_{\mathrm{IR}}$, respectively (as per above calculation). The value of ChlF during both $\Delta \mathrm{W}_{\mathrm{JI}}$ and $\Delta \mathrm{W}_{\mathrm{IP}}$ for MO17 and $\mathrm{B} 73$ was observed to be negative and positive, respectively (Fig. 4c, d). 

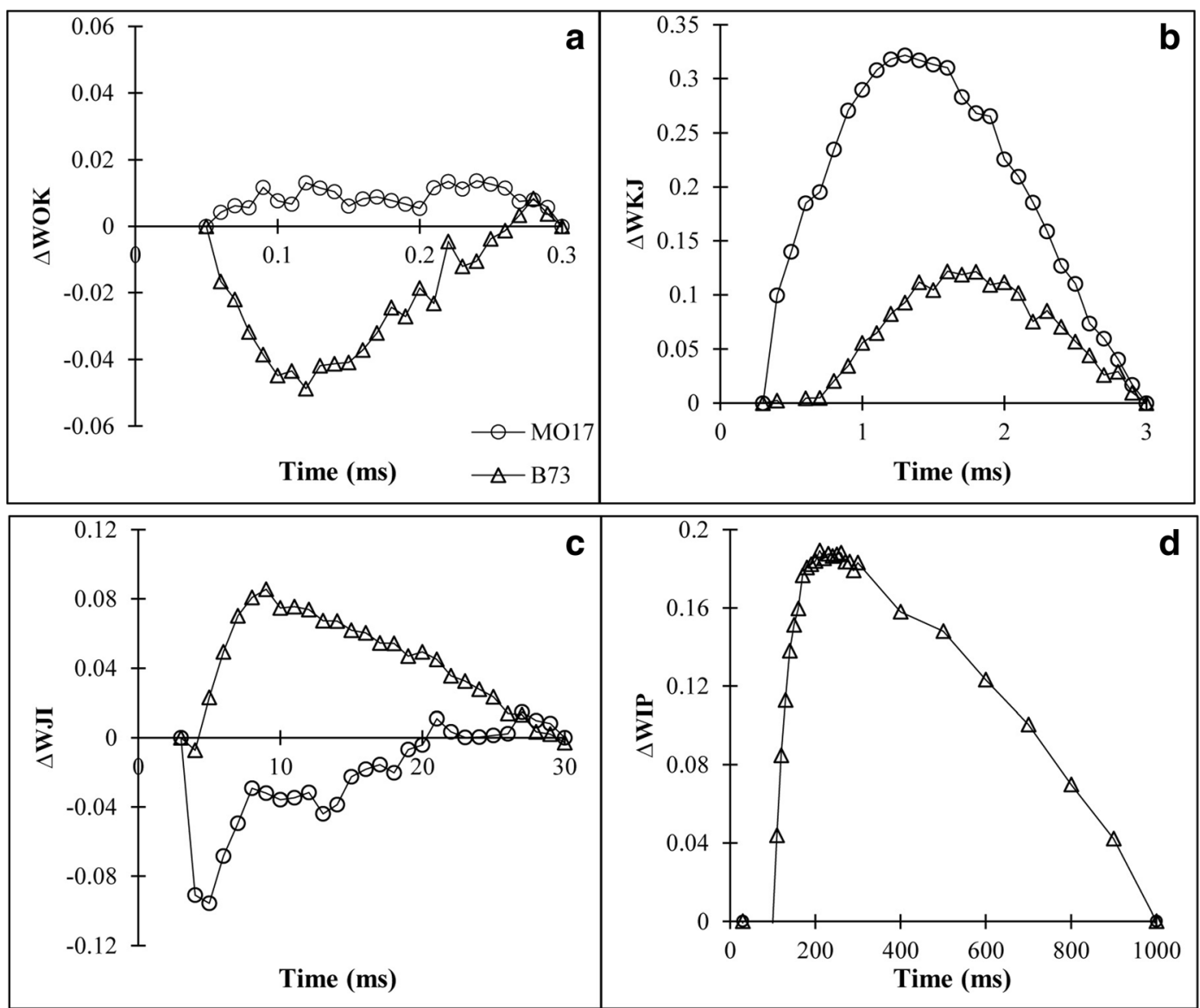

Fig. 4 Effect of $F$. verticillioides infection on normalized fluorescence transient curve: Change in the shape of the chlorophyll $a$ fluorescence transient curves normalised between $F_{\mathrm{o}}$ and $F_{\mathrm{K}}$ expressed as $\mathrm{W}_{\mathrm{OK}}\left(\mathrm{W}_{\mathrm{OK}}=\left(F_{\mathrm{t}}-F_{0}\right) /\left(F_{\mathrm{k}}-F_{0}\right)\right), F_{\mathrm{k}}$ and $F_{\mathrm{J}}$ expressed

\section{JIP-test}

The OJIP transients were translated to the following biophysical parameters based on Strasser et al. (2004), the quantum yields $\left(\phi_{\text {Po }}, \phi_{\text {Ro }}, \phi_{\text {Do }}, \Psi_{\mathrm{Eo}}\right)$; specific activities per reaction center $\left(\mathrm{ABS} / \mathrm{RC}, \mathrm{DI}_{\mathrm{o}} / \mathrm{RC}, \mathrm{TR}_{\mathrm{o}} / \mathrm{RC}, \mathrm{ET}_{\mathrm{o}} / \mathrm{RC}, \mathrm{RE}_{\mathrm{o}} /\right.$ $\mathrm{RC})$; performance indexes (PI) and structure-function indexes (VJ, $\mathrm{S}_{\mathrm{M}}$ and $\left.\mathrm{N}\right)$. The effect of $F$. verticillioides on photosynthetic electron transport of maize lines was estimated from several JIP-test parameters and presented as a spider plot in Fig. 5. The spider plot graphically represented how the response of the F. verticillioides in MO17 and B73 lines changed several important fluorescence parameters. The minimum fluorescence $\left(\mathrm{F}_{0}\right)$, the loss of energy absorbed in antennas $\left(\phi_{\mathrm{Do}}\right)$, the pool size of the electron acceptors on the reducing side of PSII $\left(\mathrm{S}_{\mathrm{m}}\right)$, the number of $\mathrm{Q}_{\mathrm{A}}$ redox turnovers until $\mathrm{F}_{\mathrm{m}}(\mathrm{N})$, the absorption flux per as $W_{\mathrm{KJ}}\left(W_{\mathrm{kJ}}=\left(F_{\mathrm{t}}-F_{\mathrm{k}}\right) /\left(F_{\mathrm{J}}-F_{\mathrm{k}}\right)\right), F_{\mathrm{J}}$ and $F_{\mathrm{I}}$ expressed as $W_{\mathrm{JI}}$ $\left(W_{\mathrm{JI}}=\left(F_{\mathrm{t}}-F_{\mathrm{J}}\right) /\left(F_{\mathrm{I}}-F_{\mathrm{J}}\right)\right)$ and $F_{\mathrm{I}}$ and $F_{\mathrm{P}}$ expressed as $W_{\mathrm{IP}}\left(W_{\mathrm{IP}}=(\right.$ $\left.\left.F_{\mathrm{t}}-F_{\mathrm{I}}\right) /\left(F_{\mathrm{P}}-F_{\mathrm{I}}\right)\right) . \Delta \mathrm{W}_{\mathrm{OX}}=W_{\mathrm{OX}}($ treatment $)-\mathrm{W}_{\mathrm{OX}}($ control $)$

reaction center $(\mathrm{ABS} / \mathrm{RC})$, and the dissipation energy flux per $\mathrm{RC}\left(\mathrm{DI}_{\mathrm{o}} / \mathrm{RC}\right)$ were observed to vary significantly, in between the two maize lines. In contrast, the activity of the water-splitting complex on the donor side of PSII $\left(\mathrm{F}_{\mathrm{V}} / \mathrm{F}_{0}\right)$ in MO17 line was observed to be much sensitive than that of B73 line. Infection of maize lines with $F$. verticillioides decreased following parameters in both maize lines: the maximum electron transport flux per reaction center $\left(\mathrm{ET}_{\mathrm{o}} /\right.$ $\mathrm{RC})$, the quantum yield of electron transport from $\mathrm{Q}_{\mathrm{A}}{ }^{-}$to the PSI end electron acceptors $\left(\mathrm{RE}_{\mathrm{o}} / \mathrm{RC}\right)$, the probability that trapped excitation moves an electron into the electron transport chain beyond $\mathrm{Q}_{\mathrm{A}}{ }^{-}{ }_{\mathrm{Eo}}$ ), the quantum yield of reduction of end electron acceptors at the PSI acceptor side $\left(\varphi_{\text {Ro }}\right)$ and performance index $\left(\mathrm{PI}_{\mathrm{abs}}\right)$. The initial slope of the fluorescent transient $\left(\mathrm{M}_{\mathrm{o}}\right)$ parameter was observed to be increased in both maize lines especially in MO17 as a result of $F$. verticillioides infection. 
Fig. 5 Spider plot for maize lines: The plot presents the mean value of OJIP-test parameters calculated from different maize lines treated with $F$. verticillioides

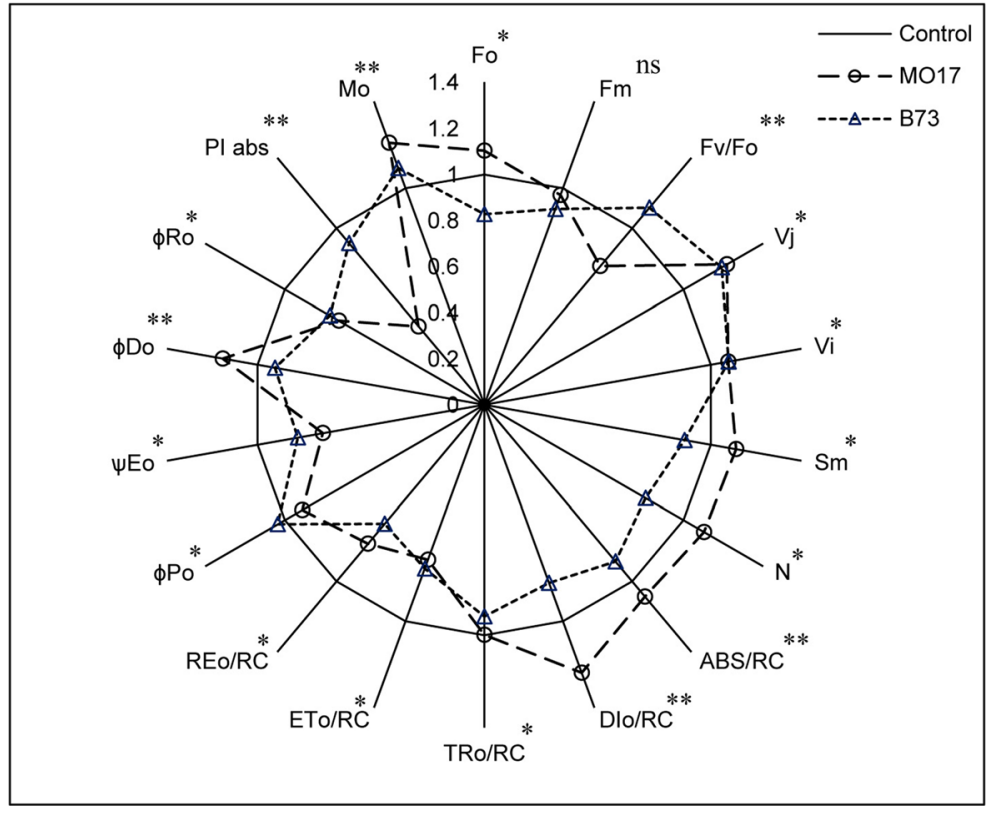

\section{Discussion}

The study shows that the effects of $F$. verticillioides on two maize lines was site specific and was dependent on the physiological reaction in the plant cells. The significant differences observed in plant pigments concentration in between control and $F$. verticillioides infected maize lines indicated that the $F$. verticillioides caused an alteration in plant metabolism, which resulted in physiological changes, leads to a difference in the biosynthesis of plant pigments (Fig. 1). The $F$. verticillioides infection leads to a significant decrease in chlorophyll concentration in maize plants, whereas carotenoids concentration were observed to be non-effected. The observation is in agreement with Mathre (1968) and Lorenzini et al. (1997), who observed a reduction of chlorophyll content in fungi infected plants. The difference in pigments are important for the validity of the chlorophyll fluorescence parameters, such $\operatorname{asF}_{0}$, and $\mathrm{F}_{\mathrm{m}}$, which depends on the chlorophyll content of the plants (Lichtenthaler 1988). Stomatal conductance of the $F$. verticillioides infected plants in both maize lines were observed to be increased when compared with control plants (Fig. 1d). A slight increase in stomatal conductance of infected maize plants indicated an increase in water loss. It has been previously reported that the water loss results in a decrease of total chlorophyll content (Sanchez et al. 1983), which was also the case in this study.

Previously several studies have shown that Fusarium species is having the capacity to damage the PSII in different plants (Santini et al. 2008; Bauriegel et al. 2011). In the last decade, the prompt chlorophyll fluorescence measurement has established itself as a quick method to estimate the plant stress responses (de Sousa et al. 2017; Kalaji et al. 2018). OJIP transient curves have been developed as a signature for plant stress, and any deviation from its usual shape indicates some abnormalities of the photosystem. A pilot study has shown that in five days the OJIP transient curve was significantly varied between the $F$. verticillioides infected and non-infected maize lines (There was no significant deviation in OJIP observed between days 1-4; data not shown), thus the measurement was performed 5 days after $F$. verticillioides inoculation. Bauriegel et al. (2011) have also shown that the changes in fluorescence after infection was only observed after the spread of 5\% of the pathogen to the plant. The normal OJIP transient curve was not much informative, as it indicated a similar pattern of curves in all studied conditions with almost similar $\mathrm{F}_{0}$ and slight variation in $\mathrm{F}_{\mathrm{m}}$ (Fig. 2a). The $F_{0}$ indicated that the number of open reaction centers after dark adaptation was similar in all the conditions, whereas, a decrease in $\mathrm{F}_{\mathrm{m}}$ indicated the $F$. verticillioides infection causes the stress response in the plant which is its initial stage with intact PSII (Bussotti et al. 2011). Therefore, the fluorescence curves from both maize lines were plotted as relative variable fluorescence $\left(V_{t}\right)$, where the difference in OJIP steps was observed to be clear, and an increase in $\mathrm{V}_{\mathrm{J}}$ and $\mathrm{V}_{\mathrm{I}}$ parameters in both maize lines suggested the accumulation of 
reduced $\mathrm{Q}_{\mathrm{A}}$ and $\mathrm{PQ}$, which was unable to transfer electrons to the dark reaction sites (Strasser et al. 2010). This is indicative of a reduction of electron transport and an increase in the energy dissipation (as heat) as a protective mechanism which contributes to the photoinhibition on the acceptor side of PSII in both maize lines (see the reduction in photosynthetic parameters such as PIabs, REo/RC in Fig. 5). Recent studies have used OJIP steps for the purpose to access the electron transport in PSII (Darwish et al. 2015; Xiang et al. 2016; Digrado et al. 2017).

Deviation in various other photosynthetic property indicators such as positive $\Delta \mathrm{Vt}$ (reflecting a decrease in electron transport) and positive $\mathrm{K}$ band (reflecting damage in oxygen evolving complex and reaction centers of PSII) indicated that maize line MO17 was more prone to damage by $F$. verticillioides in comparison to B73. Differences observed in several photosynthetic parameters such as $\mathrm{F}_{\mathrm{v}} / \mathrm{F}_{0}, \mathrm{~F}_{0}, \mathrm{~F}_{\mathrm{m}}, \mathrm{ABS} / \mathrm{RC}$ and various other shown in Fig. 5, indicated that PSII of B73 line was more resistant to damage by $F$. verticillioides in 5 days when compared with the MO17 line. The study also indicated that the PSII was damaged and the photosynthetic process was compromised as the result of F. verticillioides infection in maize lines. Thus the study presented a quick, in the field, and a non-invasive method to identify the $F$. verticillioides infection in maize plants.

Acknowledgements The project was partially covered by the grant from National Science Centre Poland, under the project UMO-2016/21/B/ ST10/02271.

\section{Compliance with ethical standards}

The research does not involve any human participants and/or animals. The materials in the article have not been published in whole or in part elsewhere and not currently being considered for publication in another journal. All authors have been personally and actively involved in substantive work leading to the manuscript and will hold themselves jointly and individually responsible for its content.

Conflict of interest The authors declare that they have no conflict of interest.

Open Access This article is distributed under the terms of the Creative Commons Attribution 4.0 International License (http:// creativecommons.org/licenses/by/4.0/), which permits unrestricted use, distribution, and reproduction in any medium, provided you give appropriate credit to the original author(s) and the source, provide a link to the Creative Commons license, and indicate if changes were made.

\section{References}

Baker, N. R. (2008). Chlorophyll fluorescence: A probe of photosynthesis in vivo. Annual Review of Plant Biology, 59, 89-113.

Baker, N. R., \& Rosenqvist, E. (2004). Applications of chlorophyll fluorescence can improve crop production strategies: An examination of future possibilities. Journal of Experimental Botany, 55, 1607-1621.

Balabanova, D. A., Paunov, M., Goltsev, V., Cuypers, A., Vangronsveld, J., \& Vassilev, A. (2016). Photosynthetic performance of the imidazolinone resistant sunflower exposed to single and combined treatment by the herbicide imazamox and an amino acid extract. Frontiers in Plant Science, 7, 1559.

Bartak, M., Hájek, J., Vráblíková, H., \& Dubová, J. (2004). Highlight stress and Photoprotection in Umbilicaria antarctica monitored by chlorophyll fluorescence imaging and changes in zeaxanthin and glutathione. Plant Biology, 6, 333-341.

Bassanezi, R. B., Amorim, L., Bergamin, F. A., \& Berger, R. D. (2002). Gas exchange and emission chlorophyll fluorescence during the monocycle of rust, angular leaf spot and anthracnose on bean leaves as a function of their trophic characteristics. Journal of Phytopathology, 150, 37-47.

Bauriegel, E., Giebel, A., \& Herppich, W. B. (2011). Hyperspectral and chlorophyll fluorescence imaging to analyse the impact of Fusarium culmorum on the photosynthetic integrity of infected wheat ears. Sensors (Basel), 11, 37653779.

Berger, B., Parent, B., \& Tester, M. (2010). High-throughput shoot imaging to study drought responses. Journal of Experimental Botany, 61, 3519-3528.

Blacutt, A. A., Gold, S. E., Voss, K. A., Gao, M., \& Glenn, A. E. (2018). Fusarium verticillioides: Advancements in understanding the toxicity, virulence, and niche adaptations of a model mycotoxigenic pathogen of maize. Phytopathology, 108, 312-326.

Borawska-Jarmułowicz, B., Mastalerczuk, G., Pietkiewicz, S., \& Kalaji, M. H. (2014). Low temperature and hardening effects on photosynthetic apparatus efficiency and survival of forage grass varieties. Plant, Soil and Environment, 60, 177-183.

Botta, A. (2013). Enhancing plant tolerance to temperature stress with amino acids: An approach to their mode of action. Acta Horticulturae, 1009, 29-35.

Bouthour, D., Kalai, T., Chaffei, H. C., Gouia, H., \& Corpas, F. J. (2015). Differential response of NADP-dehydrogenases and carbon metabolism in leaves and roots of two durum wheat (Triticum durum) cultivars (Karim and Azizi) with different sensitivities to salt stress. Journal of Plant Physiology, 179, $56-63$.

Brestič, M., Živčák, M., Kalaji, H. M., Carpentier, R., \& Allakhverdiev, S. I. (2012). Photosystem II thermostability in situ: Environmentally induced acclimation and genotypespecific reactions in Triticum aestivum L. Plant Physiology and Biochemistry, 57, 93-105.

Bussotti, F., Desotgiu, R., Cascio, C., Pollastrini, M., Gravano, E., Gerosa, G., Marzuoli, R., Nali, C., Lorenzini, G., Salvatori, E., Manes, F., Schaube, M., \& Strasser, R. J. (2011). Ozone stress in woody plants assessed with chlorophyll a fluorescence. A critical reassessment of existing data. Environmental and Experimental Botany, 73, 19-30. 
Čepl, J., Holá, D., Stejskal, J., Korecký, J., Kočová, M., Lhotáková, Z., Tomášková, I., Palovská, M., Rothová, O., Whetten, R. W., Kaňák, J., Albrechtová, J., \& Lstibůrek, M. (2016). Genetic variability and heritability of chlorophyll a fluorescence parameters in scots pine (Pinus sylvestris L.). Tree Physiology, 36, 883-895.

Darwish, M., Vidal, V., Lopez-Lauri, F., Alnaser, O., Junglee, S., El Maataoui, M., \& Sallanon, H. (2015). Tolerance to clomazone herbicide is linked to the state of LHC, PQ-pool and ROS detoxification in tobacco (Nicotiana tabacum L.). Journal of Plant Physiology, 175, 122-130.

de Sousa, C. A. F., de Paiva, D. S., Casari, R. A. D. C. N., de Oliveira, N. G., Molinari, H. B. C., Kobayashi, A. K., Magalhães, P. C., Gomide, R. L., \& Souza, M. T., Jr. (2017). A procedure for maize genotypes discrimination to drought by chlorophyll fluorescence imaging rapid light curves. Plant Methods, 13, 61.

Desai, K., Sullards, M. C., Allegood, J., Wang, E., Schmelz, E. M., Hartl, M., Humpf, H. U., Liotta, D. C., Peng, Q., \& Merril, A. H. (2002). Fumonisins and fumonisin analogs as inhibitors of ceramide synthase and inducers of apoptosis. Biochimica et Biophysica Acta, 1585, 188-192.

Digrado, A., Bachy, A., Mozaffar, A., Schoon, N., Bussotti, F., Amelynck, C., Dalcq, A. C., Fauconnier, M. L., Aubinet, M., Heinesch, B., du Jardin, P., \& Delaplace, P. (2017). Longterm measurements of chlorophyll a fluorescence using the JIP-test show that combined abiotic stresses influence the photosynthetic performance of the perennial ryegrass (Lolium perenne) in a managed temperate grassland. Physiologia Plantarum, 161, 355-371.

Duan, C., Qin, Z., Yang, Z., Li, W., Sun, S., Zhu, Z., \& Wang, X. (2016). Identification of pathogenic Fusarium spp. causing maize ear rot and potential mycotoxin production in China. Toxins (Basel), 8, 186.

Force, L., Critchley, C., \& van Rensen, J. J. (2003). New fluorescence parameters for monitoring photosynthesis in plants. Photosynthesis Research, 78, 17-33.

Gelderblom, W., Jaskiewics, K., Marasas, W., Thiel, P., Horak, R., Vleggaar, R., \& Kriek, N. (1988). Fumonisins - novel mycotoxins with cancer-promoting activity produced by Fusarium moniliforme. Applied and Environmental Microbiology, 54, 1806-1811.

Harborne, J. B. (1984). Phytochemical methods: A guide to modern techniques of plant analysis. London: Chapman and Hall.

Hazrati, S., Tahmasebi-Sarvestani, Z., Modarres-Sanavy, S. A., Mokhtassi-Bidgoli, A., \& Nicola, S. (2016). Effects of water stress and light intensity on chlorophyll fluorescence parameters and pigments of Aloe vera L. Plant Physiology and Biochemistry, 106, 141-148.

Huang, X., Shi, H., Hu, Z., Liu, A., Amombo, E., Chen, L., \& Fu, J. (2017). ABA is involved in regulation of cold stress response in Bermudagrass. Frontiers in Plant Science, 8, 1613.

Kalaji, H. M., Govindjee, Bosa, K., Koscielniak, J., \& Gołaszewska, K. Z. (2011). Effects of salt stress on photosystem II efficiency and $\mathrm{CO}_{2}$ assimilation of two Syrian barley landraces. Environmental and Experimental Botany, 73, 64-72.

Kalaji, M. H., Carpentier, R., Allakhverdiev, S. I., \& Bosa, K. (2012). Fluorescence parameters as early indicators of light stress in barley. Journal of Photochemistry and Photobiology. B, 112, 1-6.

Kalaji, H. M., Rastogi, A., Živčák, M., Brestic, M., DaszkowskaGolec, A., Sitko, K., Alsharafa, K. Y., Lotfi, R., Stypiński, P., Samborska, I. A., \& Cetner, M. D. (2018). Prompt chlorophyll fluorescence as a tool for crop phenotyping: An example of barley landraces exposed to various abiotic stress factors. Photosynthetica, 56, 953-961.

Kommedahl, T., \& Windels, C. E. (1981). Root-, stalk-, and earinfecting Fusarium species on corn in the USA. In P. E. Nelson, T. A. Toussoun, \& R. J. Cook (Eds.), Fusarium: Disease, Biology, and Taxonomy (pp. 94-103). University Park: The Pennsylvania State University Press, PA.

Lichtenthaler, H. K. (1988). In vivo chlorphyll fluorescence as a tool for stress detection in plants. In H. K. Lichtenthaler (Ed.), Applications of chlorophyll fluorescence in photosynthesis research. Stress physiology, hydrobiology and remote sensing (pp. 129-142). Dordrecht: Kluwer.

Lichtenthaler, H. K., \& Buschmann, C. (2001). Chlorophylls and Carotenoids: Measurement and Characterization by UV-VIS Spectroscopy. In R. E., Wrolstad, T. E., Acree, H., An, E. A., Decker, M. H., Penner, D. S., Reid, S. J., Schwartz, C. F. Shoemaker, \& P., Sporns, (Eds.) Current Protocols in Food Analytical Chemistry (CPFA), (pp F4.3.1-F4.3.8.) John Wiley and Sons, New York.

Lorenzini, G., Guidi, L., Nali, C., Ciompi, S., \& Soldatini, G. F. (1997). Photosynthetic response of tomato plants to vascular wilt diseases. Plant Science, I24, 143-152.

Mathre, D. E. (1968). Photosynthetic activities of cotton plants infected with Vertieillium alboatrum. Phytopathol, 58, $137-$ 141.

Oren, L., Ezrati, S., Cohen, D., \& Sharon, A. (2003). Early events in the Fusarium verticillioides-maize interaction characterized by using a green fluorescent protein-expressing transgenic isolate. Applied and Environmental Microbiology, 69, 1695-1701.

Pshibytko, N. L., Zenevich, L. A., \& Kabashnikova, L. F. (2006). Changes in the photosynthetic apparatus during Fusarium wilt of tomato. Russian Journal of Plant Physiology, 53, 2531.

Sanchez, R. A., Hall, A. J., Trapani, N., \& de Hunau, R. C. (1983). Effects of water stress on the chlorophyll content, nitrogen level and photosynthesis of leaves of two maize genotypes. Photosynthesis Research, 4, 35-47.

Santini, A., Šrobárová, A., Pavlovkin, J., Čiamporová, M., \& Ritieni, A. (2008). Fusaproliferin effects on the photosystem in the cells of maize seedling leaves. European Journal of Plant Pathology, 120, 363-371.

Schansker, G., Toth, S. Z., \& Strasser, R. J. (2005). Methylviologen and dibromothymoquinone treatments of pea leaves reveal the role of photosystem I in the $\mathrm{Chl}$ a fluorescence rise OJIP. Biochimica et Biophysica Acta, $1706,250-261$.

Schansker, G., Toth, S., \& Strasser, R. J. (2006). Dark recovery of the $\mathrm{Chl}$ a fluorescence transient (OJIP) after light adaptation: The qT-component of non-photochemical quenching is related to an activated photosystem I acceptor side. Biochimica et Biophysica Acta, 1757, 787-797.

Stirbet, A., \& Govindjee. (2011). On the relation between the Kautsky effect (chlorophyll a fluorescence induction) and photosystem II: Basics and applications of the OJIP 
fluorescence transient. Journal of Photochemistry and Photobiology. B, 104, 236-257.

Strasser, R. J., Tsimilli-Michael, M. \& Srivastava, A. (2004). Analysis of the chlorophyll a fluorescence transient. In G.C., Papageorgiou, \& Govindjee (Eds.) Chlorophyll a Fluorescence: A Signature of Photosynthesis (pp 321-362) Springer, Dordrecht.

Strasser, R. J., Tsimilli-Michael, M., Qiang, S., \& Goltsev, V. (2010). Simultaneous in vivo recording of prompt and delayed fluorescence and 820-nm reflection changes during drying and after rehydration of the resurrection plant Haberlea rhodopensis. Biochimica et Biophysica Acta, 1797, 1313-1326.

Strasser, R. J., \& Stirbet, A. D. (1998). Heterogeneity of photosystem II probed by the numerically simulated chlorophyll a fluorescence rise (O-J-I-P). Math Comput Simulat, 48, 3-9.

Xiang, L., Hu, L., Xu, W., Zhen, A., Zhang, L., \& Hu, X. (2016). Exogenous $\gamma$-aminobutyric acid improves the structure and function of photosystem II in muskmelon seedlings exposed to salinity-alkalinity stress. PLoS One, 11, e0164847.

Zhang, T., Gong, H., Wen, X., \& Lu, C. (2010). Salt stress induces a decrease in excitation energy transfer from phycobilisomes to photosystem II but an increase to photosystem I in the cyanobacterium Spirulina platensis. Journal of Plant Physiology, 167, 951-958.

Zhori, A., Meco, M., Brandl, H., \& Bachofen, R. (2015). In situ chlorophyll fluorescence kinetics as a tool to quantify effects on photosynthesis in Euphorbia cyparissias by a parasitic infection of the rust fungus Uromyces pisi. BMC Research Notes, 8, 698.

Živčák, M., Olšovská, K., Slamka, P., Galambosova, J., Rataj, V., Shao, H. B., \& Brestic, M. (2014). Application of chlorophyll fluorescence performance indices to assess the wheat photosynthetic functions influenced by nitrogen deficiency. Plant, Soil and Environment, 60, 210-215. 